\title{
O OLHAR DA COMISSÃO ASSESSORA DE AVALIAÇÃO SOBRE O ENADE DA ÁREA DE PEDAGOGIA - 2005
}

\author{
Merion Campos Bordas* \\ Ana Maria Freire da Palma Marques de Almeida** \\ Ângela Imaculada Loureiro de Freitas Dalben*** \\ Betania Leite Ramalho**** \\ Helena Lopes de FreItas***** \\ Lucíola Inês Pessoa CAVAlCANTE****** \\ MARILUCE BITTAR *******
}

Recebido em: 18 de agosto de 2008

Aprovado em: 22 de setembro de 2008

\begin{abstract}
*Doutora em Educação, Livre-Docente em Didática, Professora Titular e docente do Programa de PósGraduação em Educação Universidade Federal do Rio Grande do Sul, Presidente do Fórum de Diretores de Faculdades/Centros de Educação das Universidades Públicas Brasileiras - FORUMDIR, (1996 - 2002); Coordenadora da Comissão Assessora de Avaliação da Área de Pedagogia - INEP/MEC. (2005-2008). Email: merion.bordas@ufrgs.br

**Doutora em Educação, Livre Docente em Psicologia da Educação e Docente da Universidade Estadual Paulista Júlio de Mesquita Filho - UNESP - Bauru - SP. Membro da Comissão Assessora de Avaliação da Área de Pedagogia - INEP/MEC (2005-2008).

***Doutora em Educação e Pró Reitora de Extensão da Universidade Federal de Minas Gerais - UFMG - MG. Membro da Comissão Assessora de Avaliação da Área de Pedagogia - INEP/MEC (2005-2008). E-mail: tutti@uai.com.br
\end{abstract}

****Doutora em Educação, Presidente da Associação Nacional de Pós-Graduação e Pesquisa em Educação - ANPEd (2003-2005) e Docente da Universidade Federal do Rio Grande do Norte - UFRN- RN. Membro da Comissão Assessora de Avaliação da Área de Pedagogia - INEP/MEC (2005-2008).

*****Doutora em Educação,Presidente da Associação Nacional para Formação dos Profissionais da Educação - ANFOPE (1996-2000), e Docente da Universidade Estadual de Campinas - UNICAMP - SP. Membro da Comissão Assessora de Avaliação da Área de Pedagogia - INEP/MEC (2005-2008). E-mail: helena. freitas@uol.com.br

******Doutora em Educação e Docente da Universidade Federal do Amazonas - UFAM - AM. Membro da Comissão Assessora de Avaliação da Área de Pedagogia - INEP/MEC (2005-2008). E-mail: ppge@ ufam.edu.br

*******Doutora em Educação, Vice-Presidente da Associação Nacional de Pós-Graduação e Pesquisa em Educação - ANPEd (2003-2005) e Docente da Universidade Católica Dom Bosco - UCDB - MS. Membro da Comissão Assessora de Avaliação da Área de Pedagogia - INEP/MEC (2005-2008). E-mail: mariluce. bittar@pq.cnpq.br 
Resumo: Este artigo apresenta o trabalho realizado entre maio e novembro de 2005, pela Comissão Assessora de Avaliação do Exame Nacional de Desempenho dos Estudantes (ENADE) da área da Pedagogia, incumbida de propor diretrizes, objetivos e outras especificações para a construção dos instrumentos de avaliação a serem aplicados aos estudantes ingressantes e concluintes participantes do Exame de 2005. Após uma breve recapitulação histórica da trajetória dos Cursos de Pedagogia no país, em termos legais e situacionais, é destacado o contexto, marcado pela ausência de Diretrizes Curriculares Nacionais devidamente aprovadas, no qual ainda se situavam esses Cursos em 2005. Nesse sentido, a Comissão Assessora trabalhou sob o impacto da conjugação dos fatores da realidade e das discussões e tensões que ainda marcavam o cotidiano dos Cursos de Pedagogia, procurando contemplar as proposições do movimento nacional à luz das determinações do SINAES. Os parâmetros orientadores das matrizes para a construção dos instrumentos - conhecimentos e habilidades demandados - partiram das definições do perfil do Pedagogo e das áreas de atuação consagradas nos documentos aprovados por entidades representativas da área, os quais têm orientado a organização curricular da maioria dos cursos ora em desenvolvimento. Respeitados os princípios estabelecidos pelo SINAES e pelo ENADE na definição de uma política nacional de avaliação do Ensino Superior, a Comissão orientou todas as etapas de seu trabalho pela concepção de avaliação como instrumento de articulação de saberes, num estímulo à mútua cooperação e às práticas formativas solidárias. Tomada como uma questão pública e não só técnica, tendo como suporte o compromisso ético-político com a defesa do caráter público e social da instituição universitária, a avaliação tem, pois, conseqüências não apenas restritas ao seu âmbito, mas com repercussões importantes para a sociedade.

Palavras-chave: Avaliação da educação superior. ENADE. Pedagogia.

\title{
THE PERSPECTIVE OF THE EVALUATION ASSISTANCE COMMITTEE CONCERNING ENADE IN THE FIELD OF PEDAGOGY 2005
}

\begin{abstract}
This paper presents the work conducted between May and November of 2005 by the Evaluation Assistance Committee of the National Student Performance Exam (ENADE) in the field of Pedagogy. The purpose of the Committee is to present guidelines, objectives and other specifications that contribute to the construction of evaluation tools to be provided to in-coming and graduating students who participate in the 2005 Exam. The text begins with a brief historic recapitulation of the trajectory of Pedagogy Programs in Brazil, in legal and situational terms. The analysis emphasizes the context of these Programs in 2005, one that is marked by the absence of properly approved National Curriculum Guidelines. Given this fact the Assistance Commission addressed the impact of the various elements in this situation and the discussions and tensions that still mark the daily life of the Pedagogy Programs, considering the propositions of the national movement in light of the determinations of SINAES. The guiding parameters of the matrixes for the construction of the instruments - the knowledge and abilities required - are based on the definitions of the profile of the pedagogue and of the fields of activity consecrated in the documents approved by the representative entities in the field, which have guided the curricular organization of most of the operating programs. Respecting the principles defined by SINAES and ENADE for the establishment of a national evaluation policy for Higher Education, the Commission guided all of the phases of its work by the concept of evaluation as an instrument of articulation of knowledge, to encourage mutual cooperation and solidary educational practices. Considered as a public and not only technical issue, which is supported by an ethical and political commitment in defense of the public and social character of the university, the evaluation has consequences that go beyond this institution and has important repercussions for society.
\end{abstract}

Key words: Higher education evaluation. ENADE. Pedagogy. 


\section{Introdução}

Este artigo registra, de forma objetiva, o trabalho realizado pela Comissão Assessora de Avaliação do ENADE, no período de maio a novembro de 2005. A Comissão teve como incumbência discutir e propor diretrizes, objetivos e outras especificações necessárias à elaboração de instrumentos de avaliação a serem aplicados no Exame Nacional de Desempenho dos Estudantes (ENADE) dos Cursos de Graduação em Pedagogia, realizado em novembro de 2005, em todo o território nacional.

Mais do que mera prestação de contas formal, a elaboração deste texto constitui-se, para os membros da Comissão, em um momento de reflexão coletiva não apenas sobre os aspectos factuais relativos à trajetória de elaboração de instrumentos como também sobre os conflitos teóricos e políticos que desde os anos de 1980 têm marcado a trajetória dos Cursos de Pedagogia do país, especialmente acirrados após a promulgação da Lei de Diretrizes e Bases da Educação Nacional (Lei no 9.394/1996).

Este artigo, além de apresentar a trajetória de trabalho da Comissão, assim como os seus resultados concretos, voltados às orientações básicas para a efetivação do ENADE Pedagogia 2005 recupera, brevemente, aspectos históricos da construção da identidade dos Cursos, destacando o contexto sócio-político em que ocorreram e os embates políticos e pedagógicos que marcaram esse processo de construção/desconstrução identitária. $\mathrm{O}$ olhar histórico é igualmente válido no sentido de mostrar a perenidade de alguns conhecimentos educacionais nos currículos assim como a prevalência, ainda hoje, de um formato curricular tornado "clássico", que na realidade não corresponde aos avanços do conhecimento nas áreas de currículo e de formação de professores e não responde às exigências de uma sociedade em mutação.

Nesta perspectiva, a Comissão pretende contribuir com os educadores da área e com as instituições formadoras na promoção da necessária e urgente discussão sobre os resultados dos processos educativos que vêm desenvolvendo para a formação inicial e/ou continuada dos profissionais que atuam na Educação Básica do país, seja na Educação Infantil, nos Anos Iniciais do Ensino Fundamental e no Ensino Médio, no sistema escolar formal ou em situações de educação não-formal.

\section{A Comissão Assessora e sua Sistemática de Trabalho}

A Comissão Assessora de Avaliação da Área de Pedagogia vinculada à Diretoria de Estatísticas e Avaliação da Educação Superior (DEAES), do Instituto 
Nacional de Estudos e Pesquisas Educacionais Anísio Teixeira (INEP), foi instituída pela Portaria INEP $n^{\circ} 10$, de 14 de fevereiro de 2005, publicada no Diário Oficial de 16 de fevereiro de 2005, Seção 2, página 10. A constituição final da Comissão foi posteriormente alterada pela Portaria INEP n ${ }^{\circ} 114$, de 23 de junho de 2005 .

Os membros da Comissão foram indicados ao DEAES por entidades representativas do campo da formação de professores. Sua composição, além de atender ao critério de reunir professores pesquisadores experientes, especialistas na área, deveria contemplar as diferentes regiões do País.

Desde o início dos trabalhos ${ }^{1}$, a Comissão referendou a concepção de avaliação norteada pelo Sistema Nacional de Avaliação da Educação Superior - SINAES, considerando que este Sistema propõe, de forma coerente, uma nova e diferenciada perspectiva de avaliação, que privilegia a integração dos diferentes Instrumentos de Avaliação, como a Avaliação das Instituições, dos Cursos e dos Estudantes e a integração dos momentos da avaliação, como a Auto-avaliação Institucional realizada pelas Comissões Próprias de Avaliação (CPAs) e a Avaliação Institucional Externa.

Nesse sentido, a Comissão assumiu seu compromisso de representar a área da Pedagogia, no intento de atender efetivamente as diferentes atribuições elencadas na Portaria INEP $n^{\circ} 10$, de 14 de fevereiro de 2005, ou seja:

a) propor diretrizes, objetivos e outras especificações necessárias à elaboração dos instrumentos de avaliação do ENADE para os Cursos de Graduação em Pedagogia;

b) propor diretrizes, objetivos e outras especificações necessárias à Avaliação in loco dos Cursos de Graduação (ACG) em Pedagogia;

c) elaborar os produtos resultantes dos processos de construção do Exame Nacional de Desempenho dos Estudantes (ENADE) e da Avaliação in loco dos Cursos de Graduação (ACG). Na medida em que os membros da Comissão interagiam na praticidade do novo sistema, entendiam a amplitude determinada na $\operatorname{Lei}^{2}$ que preconiza em seu parágrafo $1^{\circ}$ do Art. $5^{\circ}$ :

$1 \mathrm{O}$ primeiro encontro da Comissão ocorreu por ocasião da realização da $1^{\mathrm{a}}$.reunião do ENADE/2005 em Brasília, DF, ocorrida nos dias 19 e 20 de maio de 2005 com a participação de todas as comissões das áreas avaliadas no ENADE em 2005: Arquitetura e Urbanismo, Biologia, Ciências Sociais, Computação, Engenharia, Filosofia, Física, Geografia, História, Letras, Matemática, Pedagogia e Química. A referida reunião teve como objetivo a apresentação do SINAES e das atribuições das Comissões, a discussão da organização dos trabalhos a serem desenvolvidos no decorrer do processo e a definição das diretrizes e recomendações para o Exame de cada área do ENADE 2005.

2 Lei no $^{\circ}$ 10.861, de 14 de abril de 2004 (DOU no 72, 15/4/2004. SEÇÂO 1, p. 3-4). 
O ENADE verificará o desempenho dos estudantes em relação aos conteúdos programáticos previstos nas diretrizes curriculares dos respectivos cursos de graduação, suas habilidades para ajustamento às exigências decorrentes da evolução do conhecimento e suas competências para compreender temas exteriores ao âmbito específico de sua profissão ligados à realidade brasileira e mundial e a outras áreas do conhecimento. (BRASIL. MEC.INEP, 2004)

O fato de constituir-se de profissionais que desenvolviam estudos relevantes na área de educação e participavam ativamente das discussões nacionais relativas à formulação e implementação de uma política pública de Estado para a educação superior, foram razões suficientes para assegurar a realização das tarefas com vistas a uma contribuição efetiva com esse novo e dinâmico sistema de avaliação. Cada membro pôde colaborar, com base em sua especialidade, sem perder de vista a troca e interação para um objetivo comum. De fato, o objetivo de traçar orientações para o ENADE da Pedagogia, dentro de uma nova perspectiva de avaliação e ainda sem Diretrizes Nacionais aprovadas para o Curso, conforme será discutido adiante, foi desafiador e estimulante para a Comissão.

Neste sentido, a partir do primeiro encontro que reuniu em Brasília todas as Comissões Assessoras envolvidas com o ENADE 2005 (maio de 2005), a Comissão entregou-se a um intenso trabalho realizando reuniões de trabalho ou participando de encontros com representantes da organização encarregada da elaboração da Prova, no caso, a CESGRANRIO. Ao todo ocorreram, no período de julho a novembro de 2005, seis encontros, realizados em Brasília/DF, Rio de Janeiro, nas instalações da DEMEC/RJ e em São Paulo que contaram, em geral, com a presença de todas as suas componentes. Cada encontro caracterizou-se por discussões e intensos estudos a fim de determinar os parâmetros para a confecção de documentos específicos que se referiam a:

a) elaboração das diretrizes para orientar os instrumentos de avaliação do ENADE para os Cursos de Graduação em Pedagogia e atender a Portaria $\mathrm{MEC} \mathrm{n}^{\circ}$ 603, de 07 de março de 2006, que no Art. $8^{\circ}$ determina:

As Comissões Assessoras de Área e a Comissão Assessora de Avaliação da Formação Geral definirão as competências, conhecimentos, saberes e habilidades a serem avaliadas e todas as especificações necessárias à elaboração da prova a ser aplicada no ENADE 2006, até o dia 31 de julho de 2006. (MEC, 2006)

b) análise e recomendações sobre o perfil dos integrantes das bancas de elaboração e de correção das provas. 
As reuniões com representantes da CESGRANRIO objetivaram, sucessivamente, a apresentação das diretrizes gerais para a prova, (conteúdos e formato das questões) discussão do modelo de questões elaborado pela Banca, apresentação e discussão dos resultados da correção amostral da Prova bem como das avaliações das respectivas questões, procedidas por membros da Comissão.

\section{Contexto do Enade Pedagogia 2005}

\subsection{Recuperando a trajetória da Pedagogia: entre conservação e tentativas de mudanças}

O curso de Pedagogia, regulamentado pela primeira vez, nos termos do Decreto-Lei n ${ }^{\circ} 1.190 / 1939$, foi estabelecido como o único lugar da "seção" Pedagogia, compondo, ao lado das seções Filosofia, Ciência e Letras, além da "seção" especial Didática, a Faculdade Nacional de Filosofia da Universidade do Brasil. Definido como um curso de bacharelado, com duração de três anos, sua finalidade primeira alinhava-se àquelas definidas para os demais bacharelados, ou seja, à preparação de "trabalhadores intelectuais para o exercício das altas atividades culturais de ordem desinteressada ou técnica" (art. $1^{\circ}$ alínea a) Mas a primazia do exercício de ordem técnica foi desde logo definida no próprio Decreto, ao determinar a exigência do diploma de Pedagogo para ingresso por concurso como técnico de educação no Ministério da Educação, assumindo funções de administração, planejamento de currículos, orientação a professores, inspeção de escolas, avaliação do desempenho dos alunos e dos docentes, de pesquisa e desenvolvimento tecnológico da educação, no próprio Ministério da Educação e nas secretarias dos estados e dos municípios.

A padronização do curso de Pedagogia em um misto de bacharelado e licenciatura, em 1939, é decorrente da concepção normativa da época, que alinhava todas as licenciaturas ao denominado "esquema $3+1$ ", pelo qual era feita a formação de bacharéis nas diversas áreas das Ciências Humanas, Sociais, Naturais, Letras, Artes, Matemática, Física, Química. Seguindo este esquema, o curso de Pedagogia formava bacharéis após três anos de um curso cujo currículo compunha-se de conteúdos da área ainda hoje conhecida como de "Fundamentos da Educação", a saber: História da Filosofia, História da Educação, Sociologia, Fundamentos Sociológicos da Educação, Filosofia da Educação, Psicologia Educacional, Fundamentos Biológicos da Educação, Educação Comparada, aos quais se acrescentavam conteúdos das disciplinas de 
Complementos de Matemática, Estatística Educacional e Administração Escolar. $\mathrm{O}$ título de licenciado era conferido aos que, tendo concluído o bacharelado, cursassem mais um ano de estudos, dedicados à Didática Geral e à Didática Especial. Ressalta-se, ainda, que aos licenciados em Pedagogia também era concedido o registro para lecionar Filosofia, História, e Matemática no primeiro ciclo do ensino secundário. ${ }^{3}$

O curso assim constituído, além de fragilizar a formação do bacharel, pelo formato generalista do currículo, dissociava o campo da ciência Pedagogia do conteúdo da Didática, abordando-os em cursos distintos e tratando-os separadamente. A dicotomia entre bacharelado e licenciatura levava a entender que no bacharelado se formava o pedagogo que poderia atuar como técnico em educação e, na licenciatura, formava-se o professor que lecionaria as matérias pedagógicas do Curso Normal de nível secundário, quer no primeiro ciclo, o ginasial - normal rural, ou no segundo.

Com o advento da Lei ${ }^{\circ} 4.024 / 1961$ e a regulamentação contida no Parecer CFE nº 251/1962, manteve-se o esquema 3+1, para o curso de Pedagogia, agora categorizado como uma licenciatura. O Parecer CFE, que pretendia definir a especificidade do bacharel em Pedagogia e visava manter uma unidade de conteúdo, aplicável como critério para transferências de alunos, em todo o território nacional, fixara o currículo mínimo do curso de bacharelado, composto por sete disciplinas, das quais cinco eram obrigatórias: Psicologia da Educação, Sociologia (Geral e da Educação) História da Educação, Filosofia da Educação e Administração Escolar. Dentre o leque de disciplinas opcionais, no mínimo duas deveriam ser escolhidas pelas instituições. Um olhar para a organização dos currículos vigentes até o final dos anos 1980, revela a adoção, pela maioria dos cursos, da disciplina de Currículos e Programas, e a presença, em alguns, da disciplina Teoria e Prática da Escola Média.

Para licenciar-se como professor para a docência na Escola Normal, o bacharel deveria completar três disciplinas obrigatórias: Psicologia da Educação, Elementos de Administração Escolar, Didática e Prática de Ensino, esta última sob a forma de Estágio Supervisionado. Mantinha-se, assim, a dualidade, bacharelado e licenciatura em Pedagogia, ainda que, nos termos daquele Parecer, não devesse haver a ruptura entre conteúdos e métodos, manifesta na exigência, para todas as licenciaturas, de desenvolver concomitantemente as disciplinas "pedagógicas" e as do bacharelado.

3 O Decreto-Lei nº 8.530/1946 - Lei Orgânica do Ensino Normal, estendeu a licenciados de outras áreas, o direito de lecionar no Curso, reduzindo o mercado de trabalho, antes exclusivo, do Licenciado em Pedagogia. 
A Lei da Reforma Universitária n ${ }^{0} 5.540$, de 1968, trouxe novas modificações no perfil do curso, ao facultar à graduação em Pedagogia, através do Parecer CFE nº 252/69, a oferta de habilitações: Supervisão Educacional, Orientação Educacional, Administração Escolar e Inspeção Educacional.

Este Parecer CFE n 252/69 e Resolução CFE nº 2/69, dispunham sobre a organização e o funcionamento do curso de Pedagogia, determinando que a formação de professores para o ensino normal e de especialistas para as atividades de orientação, administração, supervisão e inspeção, fosse feita no curso de graduação em Pedagogia, como licenciatura, o que permitia o exercício do magistério nos cursos normais, posteriormente denominados magistério de $2^{\circ}$ grau.

Observa-se, portanto, que continuavam a divisão do curso em habilitações separadas assim como a indefinição quanto à modalidade de curso e às funções a serem exercidas por seus egressos. Ao mesmo tempo, como nítidos reflexos da situação política do país assim como da tendência tecnicista que predominou na área educacional nas décadas de 1979 e 1980, reforçou-se a presença dos então chamados especialistas, na perspectiva de controle da gestão e do desempenho dos professores no âmbito da escola e também dos sistemas de ensino.

Interessa, porém, lembrar a concepção assumida pelo Parecer 252/69 de que sendo a profissão correspondente ao setor da educação uma só, daí decorre que todas as modalidades de capacitação devem partir de uma base comum, constituída por matérias básicas à formação de qualquer profissional da área e de uma parte diversificada voltada a habilitações específicas (SILVA, 1999).

O exercício do magistério nos anos iniciais de escolarização, hoje possibilitado ao egresso do Curso de Pedagogia, dependeu, a partir de então, em grande parte, das determinações dos sistemas estaduais que poderiam ou não aprovar o ingresso dos licenciados. O grande argumento orientador para essa aprovação, foi o de que "quem pode o mais pode o menos" ou de que "quem prepara o professor primário tem condições de ser também professor primário". $\mathrm{O}$ argumento pouco convincente tornou-se mais substancial na medida em que várias universidades começaram a introduzir, nos currículos de seus cursos, disciplinas como Metodologia e Prática de Ensino de $1^{\circ}$ grau, ao final da década de 1980, o que, de acordo com as normativas de cada Estado da União, permitiu a egressos do Curso de Pedagogia o exercício da docência nos anos iniciais da escolaridade.

Na realidade, o processo de desenvolvimento social e econômico do país, a partir da década de 1970, com a ampliação do acesso à escola, fez crescerem as exigências de qualificação docente, para atender às demandas de uma 
escola cuja população se expandia e se diversificava. Os movimentos sociais pelo retorno à democracia, que marcaram a década de 1980, trouxeram para o campo da educação as discussões sobre a democratização da escola e de sua gestão, aprofundando a polêmica acerca da fragmentação decorrente das habilitações oferecidas, que não davam conta de estabelecer o necessário elo entre as diferentes dimensões do trabalho escolar.

Atentas às exigências do momento histórico, várias universidades efetuaram reformas curriculares, de modo a formar, no curso de Pedagogia, professores para atuarem na Educação Pré-escolar e nas séries iniciais do Ensino de $1^{\circ}$ Grau. Como sempre, no centro das preocupações e das decisões, estavam os processos de ensinar e aprender, o trabalho pedagógico e a gestão escolar, respondendo à preocupação com a melhoria da educação inicial das crianças e dos jovens, caracterizada pelos altos índices de evasão e de repetência verificados nas escolas da classe popular.

A partir dos anos 1990, observa-se a crescente oferta de cursos de Pedagogia, os quais, além da inclusão de disciplinas e atividades escolares dirigidas à docência para crianças das faixas etárias de 0 a 5 anos e de 6 a 10 anos, passam a oferecer diversas ênfases nos percursos de formação dos graduandos em Pedagogia, para contemplar, entre muitos outros temas: a educação de jovens e adultos; a educação na cidade e no campo; a educação dos povos indígenas; a educação nos remanescentes de quilombos; a educação das relações étnicoraciais; a inclusão escolar e social das pessoas com necessidades especiais, dos meninos e meninas de rua; a educação a distância e as novas tecnologias de informação e comunicação aplicadas à educação; atividades educativas em instituições não-escolares, comunitárias e populares.

Paralelamente, observa-se a uma igualmente crescente diversificação na tipologia dos cursos, com a proposição de inúmeras e nem sempre explicáveis habilitações "inovadoras". A análise cuidadosa desse crescimento obriga a considerar, por um lado, a exigência posta pela LDB/1996, quanto à formação em nível superior para todos os professores da Educação Básica bem como o interesse dos professores já em exercício em buscarem essa formação. Por outro, a descoberta de um novo "nicho de consumo" por parte de instituições mantenedora que visavam, acima de tudo, auferir ganhos financeiros.

O paradoxo que se instala no campo educacional é que enquanto se fortificava, em nível nacional, o debate dos educadores e das entidades representativas sobre a identidade da Pedagogia, em busca de uma nova natureza para o curso, o movimento de diversificação curricular se expandiu nos últimos 20 anos a ponto de atingir, já em 2001, o número de vinte e quatro (24) distintas ofertas de 
cursos com distintas denominações/ habilitações, sempre sob a caracterização genérica de Curso de Pedagogia.

Acompanha essa diversificação curricular, o crescimento exponencial do número de cursos e de estudantes nos últimos 10 anos. À título de ilustração, observa-se que no Exame Nacional de Cursos da Pedagogia de 2001, participaram 47.870 estudantes concluintes, matriculados em 499 cursos $^{4}$. Já no ENADE 2005, dentre o contingente de 127.133 estudantes $^{5}$ que freqüentavam os Cursos, a amostra selecionada envolveu 49.497 participantes, entre ingressantes e concluintes, representantes da amostra de 891 cursos de Pedagogia, mantidos majoritariamente por universidades e distribuídos entre quatro categorias administrativas: federal, estadual, municipal e privada.

A revelação de que em torno de $66 \%$ dos estudantes de Pedagogia freqüentam cursos mantidos por instituições privadas indica, por um lado, a escassez de oferta de ensino público superior para atender o imenso contingente de professores sem a necessária formação em nível superior e, por outro, a tendência, aparentemente irreversível, de entregar a formação de professores às instituições privadas de ensino, várias delas sem qualquer tradição no campo da educação e cujos fins, muitas vezes, são primordialmente mercantis.

\subsection{Situação Legal do Curso de Pedagogia: Embates e Atravessamentos - 1996 - 2005}

Com uma história construída no cotidiano das instituições de ensino superior, não é demais enfatizar que o curso de graduação em Pedagogia, desde o início dos anos de 1990, foi se estabelecendo, na perspectiva das próprias instituições formadoras e dos movimentos de educadores e pesquisadores da área, como o principal locus da formação de profissionais capacitados a atuar plenamente nos níveis de escolaridade inicial e nas disciplinas pedagógicas para a formação de professores em nível médio, assim como para participar no planejamento, gestão e avaliação de estabelecimentos de ensino, de sistemas educativos escolares, bem como na organização e desenvolvimento de programas não-escolares.

Esse "status" foi igualmente reconhecido pelos movimentos sociais que têm insistido em demonstrar a existência de uma demanda pouco atendida, no sentido de que os estudantes de Pedagogia sejam também formados para

4 Os dados apresentados nos Relatórios do INEP relativos aos ENCs da Pedagogia indicam claramente esse crescimento pois, dos 499 registrados em 2001, passou-se a cerca de 800 , em 2003.

5 Desse total de 127.133 alunos, 43.296 freqüentariam IES públicas, enquanto 87.837 são alunos de IES privadas. 
garantir a educação, com vistas à inclusão plena, dos segmentos historicamente excluídos dos direitos sociais, culturais, econômicos e políticos.

A configuração dos cursos de Pedagogia em desenvolvimento no país passa por mudanças significativas a partir de meados da década de 1980, representadas por três grandes tendências:

a) formação de licenciados para o exercício do magistério dos Anos Iniciais do Ensino Fundamental e/ou Educação Infantil e, em alguns casos, incluindo a formação para o magistério das disciplinas pedagógicas do nível médio;

b) formação de Licenciados, habilitados nos moldes do Parecer CFE 252/69, para a docência das disciplinas pedagógicas nos cursos de Magistério em nível médio e para o exercício das funções de administradores escolares, supervisores e orientadores educacionais, e até mesmo inspetores educacionais;

c) formação, em um mesmo curso, concomitante ou sucessiva, de docentes para a escolaridade inicial e/ou para as disciplinas pedagógicas e de especialistas. Registre-se que a primeira tendência, configurada em novas habilitações profissionais tornou-se dominante na década de 1990 ainda que convivendo, em muitos casos, com o antigo modelo. Este predomínio explica-se pela consciência crescente da importância de prover uma formação em nível superior àqueles professores antes egressos dos cursos de nível médio.

A aprovação da LDB/1996, que criou os Institutos Superiores de Educação (ISE) e o Curso Normal Superior, transformou a questão das Diretrizes Curriculares Nacionais da Pedagogia em um dos temas mais polêmicos e de difícil regulamentação na área da graduação. Curso basilar da formação acadêmicocientífica do campo educacional, sua existência foi ameaçada ao lhe ser retirada sua principal tarefa, a ele atribuída pelo movimento dos educadores e assumida pelas instituições universitárias ao longo das duas últimas décadas, qual seja, a de formar professores. Importa lembrar que foi a força conjunta de instituições, entidades e movimentos de educadores que refreou certas intenções oficiais - e podemos afirmar, hoje - impediu seu desaparecimento em favor da instalação dos Cursos Normais Superiores.

Extrapolando a área da Pedagogia, a criação dos ISEs, aos quais se atribuiu a responsabilidade da formação dos professores para a Educação Básica, sob a 
justificativa de integração espacial e pedagógica do processo formador, acabou exacerbando o dualismo que caracteriza o modelo de licenciatura ainda vigente no país ${ }^{6}$, ao separar os processos de formação profissional e as atividades de produção de conhecimentos, essenciais à docência de cada área, desenvolvidas no ambiente universitário e responsável pelos significativos avanços teóricos na área da Educação nos últimos trinta anos. Este dualismo fica consagrado pelas disposições dos Decretos 3.276/99 e 3.554/2000, da Resolução 01/99/ $\mathrm{CNE} / \mathrm{CP}$, do Parecer 133/2001/CNE/CES e, mais recentemente, das Resoluções CNE/CP n.1/2002 e n.2/2002, que instituem, respectivamente, Diretrizes Curriculares Nacionais para a Formação de Professores da Educação Básica em Nível Superior em Curso de Licenciatura de Graduação Plena e a duração e a carga horária desses cursos.

Em relação ao Curso de Pedagogia, esses sucessivos ordenamentos legais, ao instituírem o Curso Normal Superior como espaço preferencial da formação de professores para os Anos Iniciais e para a Educação Infantil, além de pretenderem retirar uma função que o Curso desempenha com comprovado sucesso, consagram uma indesejável separação entre os docentes e os profissionais que se ocupariam da gestão educacional. Essa separação é indicadora de uma visão ultrapassada entre o fazer e o pensar a docência e a escola, contraditada na própria LDB/1996, como se evidencia no seu Título VI que trata dos "Profissionais da Educação". Embora estabeleça distinção entre as funções do profissional docente daquelas de outros profissionais da educação (os "especialistas"), a Lei torna claro que todos os profissionais da educação devem possuir formação docente, conforme Art. 67, § único, pelo qual a experiência docente é condição para o exercício de qualquer outra função do magistério. A formação docente, portanto, não pode deixar de ser a "base comum nacional" a qual se refere o Art. 64 da LDB/1996, quando atribui a formação de "outros profissionais da educação" aos cursos de Graduação em Pedagogia. Assim, mesmo quando incorporada à formação do pedagogo-professor a formação em nível de graduação de profissionais incumbidos das funções de administração, planejamento, inspeção, supervisão e orientação educacional para a educação básica, aqueles profissionais deverão, indubitavelmente, ser professores.

A formação docente, por sua vez, como especificado no Art. 65 da LDB/96 e nos ordenamentos legais subseqüentes, inclui, necessariamente, uma prática de ensino. Isto levou a propor, para o Curso de Pedagogia, dada a sua trajetó-

6 Deve ser observado que as Diretrizes Curriculares Nacionais para a Formação de Professores abriram novas perspectivas para a integração dessas duas atividades, impulsionando as instituições formadoras a reformularem os currículos de seus cursos de Licenciatura. 
ria histórica dos últimos vinte anos, a prática de ensino vinculada à Educação Infantil e às Séries Iniciais do Ensino Fundamental e, quando for o caso, ao magistério das disciplinas pedagógicas. Esta proposta está apoiada nas teses defendidas em vários momentos, pelo movimento dos educadores, pelas Comissões de Especialistas que assessoraram a SESu/MEC e pelas entidades representativas da área.

Em abril de 2002, a Comissão de Especialistas de Ensino de Pedagogia e a Comissão de Especialistas de Formação de Professores, representantes da área acadêmica na SESu/MEC, encaminharam ao CNE documento em que reafirmavam a posição do conjunto das entidades a respeito das áreas de atuação profissional do Pedagogo:

1. Docência na Educação Infantil, nas Séries Iniciais do Ensino Fundamental, (desenvolvida na escola regular e nas diversas modalidades, tais como a Educação de Jovens e Adultos, Educação Especial; Educação Indígena) e nas disciplinas pedagógicas para a formação de professores (conteúdos específicos da docência e do processo de ensino e aprendizagem em diferentes âmbitos: Curso Normal em nível médio e superior, programas especiais de formação pedagógica, programas de educação continuada, etc). Destaca-se que a atuação do pedagogo na Educação Superior (Normal Superior e Licenciaturas), supõe a necessária qualificação profissional em nível de pós-graduação.

2. Gestão educacional, entendida como a organização do trabalho pedagógico em termos de planejamento, coordenação, acompanhamento e avaliação nos sistemas de ensino e nos processos educativos formais e não formais;

3. Produção e difusão do conhecimento científico e tecnológico do campo educacional;

4. Atuação docente/técnica em áreas emergentes no campo educacional, em função dos avanços teóricos e tecnológicos.

O período de 2002 a 2005 foi marcado por grandes discussões e mobilizações em torno das Diretrizes para formação de professores e as Diretrizes para a Pedagogia.

Em julho de 2003, a Comissão Bicameral do CNE divulgou Minuta de Resolução que, além de consolidar as normalizações existentes, propunha organização que aprofundava a fragmentação no âmbito dos cursos de pedagogia, ao indicar a existência de licenciaturas em pedagogia à semelhança do 
Curso Normal Superior e criar a figura do bacharelado para a formação dos especialistas, em atendimento ao Art. 64 da LDB.

Tal Minuta, divulgada na página do CNE, foi submetida a uma Consulta Pública Eletrônica e Virtual. As manifestações nacionais convergiram no sentido de solicitar audiência pública, finalmente realizada em 01/12/2003 no Conselho Nacional de Educação. As entidades presentes, e inclusive um dos representantes do MEC, foram unânimes em solicitar revisão da própria LDB, bem como o adiamento da discussão para ampliar o debate entre os interessados sobre a questão, além de indicarem mudanças em pontos específicos da Minuta.

Em março de 2004, a Comissão Bicameral encerrou seus trabalhos mantendo o teor da Minuta. Recomendou, no entanto, considerando que eventual aprovação da matéria sem homologação pelo MEC acarretaria maiores transtornos, que "se instale canal próprio entre o CNE e o MEC para a busca de solução de consenso" (CNE, 10.03.2004).

Em abril de 2004, muda parcialmente a constituição do CNE, com a indicação de novos Conselheiros, do que decorre a instalação de nova Comissão Bicameral, com o objetivo de elaborar as Diretrizes para o Curso de Pedagogia. Em março de 2005, o CNE socializou Minuta de Resolução das Diretrizes Curriculares Nacionais para os cursos de graduação em Pedagogia. O documento manteve a divisão do curso em duas habilitações: educação infantil e ensino fundamental, sem incluir a dimensão da gestão educacional, reduzindo-o ao que se pretendeu estabelecer para o Curso Normal Superior.

Em nova mobilização nacional, as entidades da área organizam, em junho de 2005, em Brasília, amplo Seminário que reafirma os princípios históricos construídos para os cursos de Pedagogia: a docência como base da formação e a compreensão de que o curso de Pedagogia, porque forma o profissional de educação para atuar no ensino, na organização e gestão de sistemas, unidades e projetos educacionais e na produção e difusão do conhecimento, em diversas áreas da educação, seria, ao mesmo tempo, uma Licenciatura e um Bacharelado.

\section{Políticas Públicas de Avaliação dos Cursos de Graduação e seus Reflexos no Trabalho da Comissão Assessora}

\subsection{Antecedentes - O Exame Nacional de Cursos - Provão}

No sentido de destacar as mudanças instituídas no processo de avaliação do ensino de graduação do país entre 2003 e 2005, embora no mesmo período 
não tenham ocorrido mudanças na situação legal do Curso de Pedagogia, vale recordar a realidade que caracterizou o cotidiano dos cursos e de certo modo contribuiu para complexificar o trabalho da Comissão Assessora. Neste sentido, trata-se de lembrar que o processo de definição das diretrizes para o primeiro Exame Nacional de Cursos - Pedagogia, realizado em 2001, tal como o trabalho das Comissões de Especialistas, do Ensino que assessoraram a SESu/MEC, no período de 1998 a 2002, desenvolveu-se no quadro de aprofundamento e ampliação em nível nacional das discussões sobre as Diretrizes Curriculares Nacionais de Pedagogia.

Isto significa que os parâmetros que nortearam as decisões da Comissão de Avaliação de Curso, indicada pelo INEP, em 2001, para definir diretrizes para o primeiro Provão da Pedagogia, emergiram das proposições dominantes apresentadas até o momento no âmbito das entidades e das Comissões de Especialistas, tal como relatado na seção anterior.

A Comissão de Avaliação do ENC Pedagogia de 2002, constituída basicamente pelos mesmos professores especialistas que trabalharam em 2001, decidiu não introduzir alterações na definição das Áreas de Atuação do egresso do Curso, já utilizadas para orientar as diretrizes de 2001, dado a que a situação legal deste continuava inalterada. Mas, sensível às solicitações da área e à necessidade de identificar as demandas de formação, procedeu a "aperfeiçoamentos" em relação ao Perfil do egresso, aperfeiçoamentos que resultaram na definição das seguintes capacidades:

a) compreensão dos vários domínios do conhecimento pedagógico e dos conteúdos disciplinares específicos e respectivas metodologias, numa perspectiva de formação contínua e auto-aperfeiçoamento;

b) participação na implementação de projetos educativos que contemplem a diversidade e as inter-relações das distintas esferas do social: cultural, ética, estética, científica e tecnológica;

c) mobilização e integração de conhecimentos, capacidades e tecnologias para intervir efetivamente em situações pedagógicas concretas;

d) articulação, mediante práticas participativas, de recursos humanos, metodológicos, técnicos e operativos;

e) investigação de situações educativas, sabendo mapear contextos e problemas, captar e analisar as contradições, argumentar e produzir conhecimento; 
f) atuação ético-profissional, implicando responsabilidade social para a construção de uma sociedade includente, justa e solidária." (Relatório Final Pedagogia 2002)

Também a Comissão de Especialistas encarregada de elaborar os instrumentos orientadores da prova do ENC 2003 da Pedagogia seguiu acatando esse mesmo Perfil de egresso, determinante para definir saberes e habilidades demandados ao concluinte do curso. À época, a Comissão decidiu-se por tão somente dar nova redação a alguns dos objetivos propostos anteriormente assim como procedeu à revisão dos conteúdos. Tais atividades não produziram, no entanto, modificações substanciais no espírito e no teor do Exame.

\subsection{Os Avanços do SINAES Refletidos no ENADE}

No decorrer de 2004, iniciou-se a implantação do novo modelo de exame de estudantes dos cursos de graduação como implementação de uma nova política de avaliação da educação superior do país. Tal modelo se apresenta como um avanço em relação à concepção que vinha conduzindo as experiências anteriores no âmbito do sistema Nacional de Avaliação instaurado em 1995, antes mesmo da aprovação da LDB/1996.

Para melhor compreender como o modelo se refletiu em um dos seus instrumentos importantes, o Exame Nacional de Avaliação do Desempenho dos Estudantes, é importante registrar que as proposições iniciais do SINAES foram elaboradas por uma Comissão Especial de Avaliação da Educação Superior - (CEA) instalada pelo Ministério da Educação. Esta Comissão apresentou ao Ministério da Educação, em 27 de agosto de 2003, documento denominado "Bases para uma proposta de avaliação da educação superior" (SINAES, 2004, p. 7), que foi submetido à consulta e discussão na academia, na sociedade civil organizada, nos sindicatos, nas sociedades científicas, no parlamento e na sociedade em geral, inclusive aos que participaram da implementação dos instrumentos avaliativos do Exame Nacional de Cursos (ENC), da Avaliação das Condições de Ensino (ACE) e do Plano de Desenvolvimento Institucional (PDI). A primeira publicação do SINAES, em 2003, deixou claro que o objetivo principal seria o de organizar as bases para um sistema mais global, mais integrado e mais democrático de avaliação, mas "[...] fortemente identificado com a idéia da função social das IES". Os princípios estabelecidos pelo SINAES orientaram a materialização das formas e instrumentos, tais como o ENADE, coerentes com a concepção de Sistema adotada. 
O que difere basicamente o Exame Nacional de Desempenho dos Estudantes (ENADE) do Exame Nacional de Cursos (ENC), aparece na própria legislação, ${ }^{7}$ que deixa clara a função diagnóstica do ENADE, diferente daquela instituída pelo ENC, conforme apontam Limana e Brito (2005, p. 14):

O (ENADE) procura ser diagnóstico, de forma que seus resultados permitam correção e superação das dificuldades. O modelo antigo de exame (ENC) era aplicado uma única vez ao final do curso e isto não permitia correção e superação das dificuldades do estudante avaliado.

A função diagnóstica do ENADE não visa a uma avaliação pontual, voltada à aferição do "produto", mas a uma avaliação mais formativa e integrada às outras dimensões avaliativas propostas pelo SINAES. Por isso, e para ser fiel e garantir a qualidade do novo sistema, que entre outras coisas destaca a dimensão cognitiva, é que no ENADE participam estudantes ingressantes e concluintes, permitindo análises enfocadas nas aprendizagens desenvolvidas pelo o estudante durante o curso e a verificação do papel da IES no processo de construção do conhecimento. Também, o novo modelo de Exame dá margem a que os dados obtidos do questionário dos alunos e dos coordenadores de curso sejam analisados em conjunto a fim de a IES possa elaborar sua própria estratégia de melhorias em seu projeto-pedagógico. Essa dimensão que favorece a auto-regulação das instituições formadoras no sentido do aperfeiçoamento de sua função de ensino, se opõe à tendência ao estabelecimento de ranqueamentos entre as instituições e seus cursos de graduação, que tão fortemente marcou a aplicação dos ENCs. Como afirmam Limana e Brito (2005, p. 13):

A ordenação das escolas de acordo com o desempenho expresso através de uma nota obtida através de uma única prova e a formulação de listas que mostram a posição dos cursos em um ranking não acrescenta muito ao desenvolvimento das Instituições e ao debate educacional, mesmo quando elaboradas sob a alegação de transparência e objetividade.

\section{O Trabalho da Comissão Assessora de Avaliação da Área de Pedagogia - Enade 2005}

Coube à Comissão Assessora de Avaliação indicada em 2005 ocupar-se da primeira experiência de propor diretrizes para a organização da Prova de

$7 \quad$ Art. $5^{\circ}$. da Lei no. 10.861 de 14 de abril de 2004. 
Conhecimentos específicos do Curso de Pedagogia dentro de uma nova concepção de avaliação.

Mencionar as condições em que se encontravam os Cursos de Pedagogia do país, no momento em que essa nova Comissão iniciou suas atividades, a partir de 20 de maio de 2005, implica reiterar que não ocorrera qualquer modificação legal quanto às finalidades e à organização curricular que vinha sendo adotada pela maioria dos Cursos, desde as avaliações promovidas pelo INEP de 2001 a 2003.

Continuava-se sem a aprovação das Diretrizes Curriculares Nacionais, e o terreno dos debates era marcado pela discussão nacional relativa às propostas sucessivamente apresentadas pela segunda Comissão Bicameral encarregada pelo CNE de definir a questão. Por outro lado, a grande maioria das instituições, especialmente as universidades públicas e privadas, desenvolvia seus cursos atendendo, em maior ou menor grau, as orientações propostas pelos documentos emanados das entidades mais representativas da área-ANFOPE, FORUMDIR, ANPEd - assim como das duas Comissões de Especialistas que haviam sucessivamente atuado na SESu/MEC, no período de 1998 a 2002.

A tradução desse acatamento institucional a uma normalização ainda não oficial, fica evidente na configuração dos cursos submetidos ao ENADE 2005, majoritariamente voltados à formação de pedagogos professores para atuarem na Educação Infantil e nos Anos Iniciais do Ensino Fundamental e, em muitos casos, também na Educação de Jovens e Adultos ${ }^{8}$ e na Gestão Educacional, envolvendo a organização do trabalho pedagógico na escola, nos sistemas de ensino e nos processos educativos formais e não formais.

Consciente dessas circunstâncias, a Comissão Assessora do ENADE Pedagogia trabalhou durante o ano de 2005, sob o impacto da conjugação dos fatores da realidade e das discussões e tensões que ainda marcavam o cotidiano dos Cursos de Pedagogia e dos educadores, procurando contemplar, na formulação dos instrumentos orientadores do Exame as proposições do movimento nacional à luz das determinações do SINAES.

Destaca-se novamente que a orientação proposta pelo SINAES para a avaliação do ensino superior difere substancialmente daquela conduzida até 2003, quando os Exames Nacionais de Curso assumiram uma proeminência legal e social acima de qualquer outra modalidade ou instrumento previsto no Sistema Nacional de Avaliação do Ensino Superior. Conseqüentemente, a vocação e as características do ENADE seriam distintas daquelas dos ENCs.

8 Em alguns casos, também a Educação Indígena e a formação pedagógica voltada para atuação no Curso Normal em nível médio e/ou em programas especiais de formação continuada de professores. 
Além de estabelecer o procedimento de amostragem de estudantes submetidos ao Exame, a periodicidade do mesmo e de buscar aferir os conhecimentos gerais detidos pelos estudantes ${ }^{9}$, a Lei ${ }^{\circ} 10.861$, de 14 de abril de 2004, determina que o ENADE

[...] aferirá o desempenho dos estudantes em relação aos conteúdos programáticos previstos nas diretrizes curriculares do respectivo curso de graduação, suas habilidades para ajustamento às exigências decorrentes da evolução do conhecimento e suas competências para compreender temas exteriores ao âmbito específico de sua profissão, ligados à realidade brasileira e mundial e a outras áreas de conhecimento. (par. $1^{\circ}$, Art. $5^{\circ}$ )

Este objetivo geral foi complementado pela Portaria $n^{0} 2.051$, de 9 de julho de 2004, que atribui ao ENADE a tarefa de acompanhamento do processo de aprendizagem e o desempenho dos estudantes em relação aos conteúdos e habilidades, o que resulta na inclusão de estudantes ingressantes e concluintes no Exame.

O fato é que, apesar dessa nova opção político-metodológica, entendida e respeitada pela Comissão, a questão básica permanecia: estabelecer que saberes e habilidades deveriam nortear a organização da prova do ENADE 2005 da Pedagogia, o que, traduzido na linguagem da Portaria 2051/04, significaria estabelecer os conteúdos programáticos previstos nas inexistentes diretrizes curriculares do curso.

Frente a essa questão, a Comissão percebeu que se encontrava quase no mesmo patamar a partir do qual foram procedidos os Exames precedentes realizados pelo INEP. Diante da ausência de definição legal quanto aos conteúdos curriculares indicados pelo CNE, a Comissão valeu-se de documentos representativos da área, de conhecimentos que detinha sobre os currículos de diferentes cursos existentes e, ao mesmo tempo, retomou, em parte, dados aprendidos nas experiências anteriores dos ENCs. Esses recursos foram tomados como sinalizadores para a determinação das matrizes relativas aos conhecimentos e habilidades considerados essenciais no processo de formação do futuro pedagogo.

Assim, os instrumentos definidores das matrizes partiram das definições do perfil do Pedagogo e de suas áreas de atuação já consagradas nos documentos

9 A organização geral do ENADE prevê a aplicação de uma prova composta de duas partes: a primeira, voltada para aferição de conhecimentos sobre a realidade social e a esfera da cultura; a segunda, para aferição dos conhecimentos de conteúdos e habilidades específicas de cada área. 
aprovados e acima referidos. Essas decisões estão expressas no Edital do Exame Nacional de Desempenho dos estudantes de Pedagogia - ENADE 2005 e serão analisadas na próxima seção deste texto.

\section{Construindo e Avaliando os Instrumentos da Prova}

\subsection{Elaboração do Edital no 177/05}

A primeira das atribuições da Comissão “[...] propor diretrizes, objetivos e outras especificações necessárias à elaboração dos instrumentos de avaliação a serem aplicados no Exame Nacional de Desempenho dos Estudantes de Pedagogia dos Cursos de Graduação em Pedagogia” (ENADE, 2005), apresentou-se como um grande desafio, uma vez que as Diretrizes Curriculares não tinham sido aprovadas. Ora, se mesmo partindo de diretrizes curriculares estabelecidas, a elaboração de um instrumento de avaliação a ser utilizado em todo Brasil, com a diversidade cultural e as desigualdades regionais que o caracterizam, já se constitui tarefa vultosa, sem elas a situação que se apresentava era bastante delicada.

Como ponto bastante positivo para cumprir a tarefa, havia a composição da Comissão, na qual as várias regiões de nosso país se vêem representadas, e o rápido entrosamento do grupo, com suas variadas experiências e conhecimentos. O trabalho iniciou com a discussão dos caminhos a serem tomados, a começar pela construção da Portaria que estabelece as Diretrizes para o Exame Nacional de Desempenho do Estudante do Curso de Pedagogia. Cabia, portanto, elaborar objetivos no componente específico da área; "definir" o Perfil de pedagogo a ser formado; determinar os conhecimentos e habilidades a serem incluídos na área de formação geral para as diferentes habilitações ainda existentes e nas áreas específicas. Estas últimas foram subdivididas em áreas específicas para a docência e áreas específicas para a Gestão Escolar e em outros espaços educativos.

Após consulta à LDB/1996 e aos documentos produzidos pelas entidades representativas da área, foram consultadas as Resoluções do CNE/CP n.1/2002 e n.2/2002, que instituem, respectivamente, Diretrizes Curriculares Nacionais para a Formação de Professores da Educação Básica em Nível Superior em Curso de Licenciatura de Graduação Plena e a duração e a carga horária desses cursos.

Essas consultas foram fundamentais para ampliar o entendimento da Comissão por mostrarem os fundamentos teóricos, as concepções de formação de 
professores e as diferentes posições em relação ao debate sobre as diretrizes do Curso de Pedagogia e orientaram a definição dos objetivos gerais para a Prova do ENADE 2005, constantes do Artigo $4^{\circ}$. da Portaria INEP ${ }^{\circ} 177$ de 24/08/2005, a saber:

a) contribuir para a avaliação do desempenho dos estudantes de graduação em Pedagogia, levantando indicadores para ações que visem a melhoria da qualidade do ensino a eles oferecido;

b) identificar necessidades e problemas relacionados ao processo de formação do pedagogo, considerando as exigências sócioeconômicas, políticas, culturais e éticas, os princípios expressos nas Diretrizes Curriculares Nacionais para a Formação de Professores da Educação Básica e nas Diretrizes Curriculares para a Educação Infantil e para o Ensino Fundamental bem como os documentos propositivos sobre diretrizes curriculares nacionais para a Pedagogia, produzidos e divulgados pelas entidades da área.

Para a elaboração do previsto no Artigo $5^{\circ}$. da Portaria, a Comissão partiu do pressuposto de que cabia ao Pedagogo assumir postura profissional ética pautada na responsabilidade social para com a construção de uma sociedade inclusiva, justa e solidária, ao exercer suas atividades nas seguintes áreas ou campos profissionais:

a) na docência da Educação Infantil (0 a 6 anos), dos Anos Iniciais do Ensino Fundamental regular e de Jovens e Adultos e na docência das disciplinas de Formação Pedagógica em nível médio;

b) no planejamento, organização, avaliação e gestão nos sistemas de ensino em escolas e outros espaços educativos;

c) na produção e difusão do conhecimento no campo da educação.

Quanto à definição do Perfil profissional do Pedagogo, a Comissão omitiu o uso do termo "competências", referido nos documentos oficiais, por entender tratar-se de conceito ainda sujeito a múltiplas e contraditórias interpretações no meio educacional. Como assinalam Jonnaert et al. (2005), desde sua aparição no campo da educação, no início dos anos 1990, o conceito tem sofrido fortes 
críticas e muitos pesquisadores têm assinalado a necessidade de analisá-lo com maior profundidade antes de introduzi-lo na orientação de programas para o ensino, em qualquer um de seus níveis. Também apontam o viés de uma lógica mercadológica e econômica que tem sido o pano de fundo para sua apropriação por determinadas políticas oficiais para a educação.

Nas dimensões em que vinha sendo discutido pela Comissão, o processo de formação capaz de assegurar o correto desempenho profissional do pedagogo deveria ter como referência o Perfil de um graduando capacitado a:

- compreender o contexto sócio-cultural, político e econômico em que se inserem os processos educativos escolares e nãoescolares, bem como compreender e respeitar as diferenças sócio-culturais dos alunos para orientar sua formação, visando a qualidade da educação;

- entender a formação profissional como um processo contínuo de auto-aperfeiçoamento e de domínio teórico investigativo do campo da educação;

- compreender as diversas abordagens do conhecimento pedagógico assim como os conteúdos específicos dos currículos dos diferentes níveis de ensino e suas respectivas metodologias;

- participar no planejamento, na implementação e avaliação de projetos educativos escolares e não escolares de modo que a diversidade e as múltiplas relações das esferas do social: cultural, ética, estética, científica e tecnológica sejam contempladas;

- planejar e desenvolver situações pedagógicas concretas, para situações educativas escolares e não-escolares, integrando diferentes conhecimentos e tecnologias de informação e comunicação;

- articular, mediante práticas participativas, recursos humanos, metodológicos, técnicos e operativos, inclusive em equipes interdisciplinares e multi-profissionais;

- investigar situações educativas, mapeando contextos e problemas, analisando contradições, argumentando e produzindo conhecimentos.

A fim de encaminhar o teor do artigo $6^{\circ}$, que trata do componente específico da prova na área de Pedagogia, tendo em vista o difícil contexto político, em 
função do embate entre diferentes posições acadêmicas e pedagógicas sobre o tipo de profissional a ser formado nos cursos, discutiu-se qual a melhor terminologia a ser tomada como categoria orientadora da base epistemológica da prova. A intenção da Comissão Assessora de Avaliação era a de tornar o mais claro possível para a Banca elaboradora da prova os fundamentos que deveriam nortear o processo avaliativo do estudante iniciante ou concluinte, a saber:

a) a interdisciplinaridade;

b) a práxis pedagógica como referência;

c) os conteúdos programáticos previstos nos documentos representativos e propostos nas associações da área e presentes na maioria dos desenhos curriculares dos cursos de Pedagogia;

d) os saberes e habilidades necessários ao desempenho profissional e ao conhecimento da realidade brasileira.

Considerando a necessidade de atender-se às especificações do SINAES e do ENADE, optou-se por utilizar, na formulação dos objetivos, a terminologia conhecimentos e habilidades em razão de sua vinculação com os campos disciplinares que compõem as diferentes propostas de curso:

\section{I - Conhecimentos pedagógicos de formação geral:}

a) conhecer a realidade dos diferentes espaços de atuação e suas relações com a sociedade, de modo a propor intervenções educativas fundamentadas em conhecimentos filosóficos, sociais, históricos, econômicos, políticos, artísticos e culturais;

b) conhecer e analisar as políticas educacionais e seus processos de implementação;

c) compreender o desenvolvimento e a aprendizagem de crianças, jovens e adultos, considerando as dimensões cognitivas, afetivas, socioculturais, éticas e estéticas;

d) articular as teorias pedagógicas e de currículo no desenvolvimento da docência, na elaboração e avaliação de projetos pedagógicos, na organização e gestão do trabalho educativo escolar e não-escolar.

\section{II - Conhecimentos pedagógico-didáticos:}

a) participar da formulação, implementação e avaliação contínua de projetos pedagógicos escolares e não escolares; 
b) planejar, desenvolver e avaliar situações de ensino e de aprendizagem, de modo a adequar objetivos, conteúdos e metodologias específicos das diferentes áreas à diversidade dos alunos e aos fins da educação;

c) incorporar as tecnologias de informação e comunicação ao planejamento e às práticas educativas;

d) analisar situações educativas e de ensino e realizar estudos e pesquisas, de modo a produzir conhecimentos teóricos e práticos.

\section{III - Conhecimentos das áreas específicas:}

a) conhecer e articular conteúdos e metodologias específicas das áreas de conhecimento envolvidas nos diferentes âmbitos de formação e atuação profissional;

b) proceder à seleção e organização de conteúdos e de estratégias para a aprendizagem, considerando as múltiplas dimensões da formação humana;

c) estabelecer a articulação entre os conhecimentos e processos investigativos do campo da educação e das áreas do ensino;

d) promover e planejar ações visando a gestão democrática nos espaços e sistemas escolares e não-escolares.

\section{Área de Formação Geral:}

- Filosofia da Educação

- História da Educação /História da Educação Brasileira

- História da Pedagogia e do Curso de Pedagogia no Brasil

- Sociologia da Educação/ Políticas Públicas em Educação

- Psicologia da Educação/ Desenvolvimento

- Psicologia da Educação/ Aprendizagem

- Teorias Pedagógicas

- Organização e gestão da Escola/ Projeto Político Pedagógico

- Projeto Político Pedagógico/ Teorias e práticas de currículo

- Tecnologias da informação e comunicação nas práticas educativas 
- Didática/ Organização do trabalho docente

- Avaliação do Ensino e da Aprendizagem

- Organização da Educação Brasileira/ Legislação Educacional

- Pesquisa como princípio educativo

\section{Áreas específicas para a docência}

- Construção do "ser" docente/ especificidades do trabalho docente

- Educação Infantil

- Alfabetização e Letramento

- Educação Matemática

- Ciências/ Temas transversais

- Geografia e História/ Temas transversais

- Linguagens artístico-culturais (incluir Literatura/ corporeidade)

- Educação de Jovens e Adultos/ ensino fundamental.

\section{Áreas específicas para a Gestão Escolar e em outros espaços educativos}

- Coordenação, elaboração e avaliação do Projeto Político-Pedagógico

- Implementação e avaliação do currículo

- Apoio pedagógico aos processos de ensino e de aprendizagem

- Organização e práticas de gestão nas escolas e em outros espaços educativos

- Relação escola-comunidade e movimentos sociais

- Investigação, produção e difusão de conhecimentos pedagógicos e educacionais.

De acordo com as determinações legais do ENADE, a Prova da Pedagogia 2005 obedeceu ao seguinte formato: divisão em duas partes, uma comum a todos os cursos e outra específica da Pedagogia envolvendo os três domínios de conhecimentos. A prova de conhecimento específico apresentou 28 questões de múltipla escolha e duas questões discursivas de modo a possibilitar a avaliação das habilidades e dos conhecimentos definidos pela Portaria INEP $\mathrm{n}^{\mathrm{o}} 177 / 2005$. 


\section{Distribuição de peso das questões na Prova:}

Múltipla Escolha: 60\% - Discursivas: 40\%

\section{Composição dos tipos de questões da prova e distribuição do número de questões de Múltipla Escolha:}

Complementação Simples: 07 questões

Resposta Única: 07 questões

Interpretação: 07 questões

Resposta Múltipla: 07 questões

A Comissão optou pela não inclusão na prova de questões do tipo asserção-razão, considerando que não é usual na área podendo provocar distorções nos resultados. Na definição dos níveis de dificuldade das questões da prova, a Comissão avaliou a pertinência do predomínio do nível médio de dificuldade, já que deveria ser considerado o fato de a prova envolver estudantes iniciantes e finalistas dos cursos. A Comissão ponderou, ainda, sobre a diversidade de propostas e de organização curricular dos cursos de Pedagogia oferecidos no país, bem como as diferenças entre instituições mantenedoras dos mesmos.

Número de questões por nível de dificuldade (difíceis, média complexidade, fáceis):

Difícil: 05 questões de Múltipla Escolha

Média Dificuldade: 14 questões de Múltipla Escolha e 02 Discursivas

Fácil: 09 questões de Múltipla Escolha

\section{Distribuição dos conteúdos das questões:}

Múltipla Escolha:

Formação geral: 14 questões; Docência: 08 questões; Gestão: 06 questões

Discursivas: Docência: 01 questão; Gestão: 01 questão

A distribuição do número de questões em relação ao conjunto dos conteúdos propostos no artigo $7^{\circ}$. da Portaria, tomou por base as possibilidades de articulação entre campos do conhecimento teóricos e práticos a fim de atender as orientações do ENADE de modo que as questões fossem elaboradas envolvendo a incorporação de estudos de caso, situações-problemas, interpretação de textos e imagens. 
A Comissão estabeleceu, também, as seguintes Recomendações de cunho geral a serem observadas pela Banca Elaboradora da Prova:

- A prova deveria contemplar conhecimentos básicos, relevantes à formação profissional, evitando questões genéricas e/ou especulativas;

- Cuidar para que as questões baseadas no Art. $7^{\circ}$ da Portaria $n^{\circ}$ 177/2005 tenham correspondência com o estabelecido nos Art. $5^{\circ}$ e $6^{\circ}$ da mesma;

- Apresentar situações concretas, problematizadoras para que o estudante responda com base nas teorias e/ou experiências vividas;

- Explorar, nas questões discursivas, as possibilidades de situaçõesproblema, que demandem análise, argumentação e proposição de soluções;

- Evitar que os enunciados das questões se refiram especificamente a determinados autores, como por exemplo: Segundo Piaget ..., De acordo com Vygotski [...];

- As questões deveriam favorecer a articulação entre os diferentes conteúdos.

Diretrizes e recomendações foram apresentadas em reunião com membros da instituição/ empresa responsável pela elaboração da prova e, embora este encontro tenha ocorrido em clima de abertura e entendimento, era grande a expectativa da Comissão Assessora quanto ao grau de aceitação, pelos elaboradores da prova, das recomendações feitas. Bem sabemos das dificuldades de elaboração de um instrumento com tamanha abrangência. Portanto, o cuidado para que as recomendações à Banca elaboradora da prova fossem bastante claras, capazes de expressar as concepções e os princípios que nortearam a formulação das diretrizes para o Exame. A Comissão defendia o reconhecimento e a valorização da diversidade cultural, a formulação de questões problematizadoras, que não se restringissem a determinadas teorias ou a especificidades regionais, que fomentassem o raciocínio, o espírito crítico, a argumentação, e cujo enunciado, em si mesmo, fosse via de aprendizagem. Defendia, pois, uma avaliação marcadamente formativa, em que o(a) estudante encontrasse sentido no que estava sendo avaliado.

Em função das recomendações, a Comissão Assessora foi convidada, pela equipe elaboradora, para nova reunião na qual lhe foi apresentada uma amostra de "questões-espelho" para serem avaliadas e aprovadas como possíveis 
questões de prova. Mas, finalmente, foi apenas no dia de realização do Exame que a Comissão Assessora pôde conhecer a prova em sua totalidade, e só então, tornou-se possível avaliar a avaliação.

\subsection{Avaliando a Prova e Discutindo Avaliação}

De um modo geral, foi positiva a reação de todos os componentes da Comissão Assessora diante do instrumento aplicado, considerando que as questões, tanto da parte de Formação Geral quanto da Parte específica, em sua maioria, estavam bem formuladas, correspondendo, estas últimas, ao que houvera sido proposto/solicitado pela Comissão. Vale ressaltar que a análise do instrumento foi posterior à sua aplicação e, após exames minuciosos, do total de 40 questões, apenas duas foram, a pedido e sob argumentação, anuladas (questões 10 e 35). Foram, ainda, apresentadas análises críticas a respeito das questões 20 e 21 por destoarem do conjunto da prova que, na sua totalidade, apresentava uma ênfase em questões de natureza reflexiva. Como as questões referidas demandavam respostas demasiado sintéticas, favoreciam explicações reducionistas. Também as questões 8 e 25 foram consideradas mal formuladas pela Comissão Assessora em razão da escolha do texto. A primeira, por utilizar texto de autor pouco familiar aos estudantes de Pedagogia, além de apresentar linguagem hermética, e a segunda, por haver sido considerada mal elaborada, apresentando uma situação que sustentava posição preconceituosa em relação ao personagem do texto.

Reconhecemos, como já afirmamos anteriormente, as dificuldades de elaborar uma prova a ser aplicada nacionalmente, haja vista a pluralidade cultural de nosso país, a diversidade de opções de formação e de propostas curriculares. O próprio balanceamento entre questões "fáceis", de "dificuldade média" e "difíceis" apresenta, também, seus desafios, uma vez que a avaliação está relacionada aos objetivos estabelecidos para cada curso. O que determina a facilidade ou a dificuldade? Uma questão é fácil ou difícil em relação a que? Mediante quais parâmetros?

Não se pode esquecer que contextos sócio-educacionais diversos demandam metodologias e critérios de avaliação próprios, a serem construídos com a participação da comunidade educativa, especialmente dos(as) professores(as). Afinal, não se avalia de forma neutra. Avalia-se por que? Para que? Para quem? A favor de que e de quem? Contra o que e contra quem? - diria Freire (1992, p. 98) Quais os efeitos da avaliação? Quem participa do processo avaliativo e em que nível? 
Mais do que buscar categorizações que enquadrem diferentes formas e políticas de avaliação, o que importa ressaltar é que estas precisam ser reconhecidas em sua intencionalidade, principalmente quando a avaliação é compreendida como prática democrática que se vai, como defende Dias Sobrinho (2000, p. 17), "[...] construindo coletivamente e esteja sempre orientada à produção da qualidade educativa, ao melhoramento institucional e à permanente formação dos agentes da comunidade universitária."

Sem pretender chegar a uma proposta que receba aprovação geral e que esteja isenta de questionamentos, o desejável é que uma avaliação represente o esforço da busca por consensos relativos, assentados sobre princípios básicos e transparentes e possibilitem a articulação das diversas dimensões da universidade, na perspectiva da integralidade, e em atendimento à sua função pública e social.

Nunca é demais reforçar que o caráter fundamentalmente formador da instituição universitária é tecido numa complexa rede de significados e significações, que acentuam sua função pública e social. E é através de sua dimensão formativa que a universidade deve levar em conta a relevância social do conhecimento que produz, tomando-a como critério de qualidade.

Assim, para além dos dados quantificáveis, daquilo que pode ser aferido, medido, as políticas de avaliação da educação superior precisam penetrar nos significados produzidos no interior de cada instituição universitária, nas suas finalidades e "vocações" específicas, nos seus programas e planos de ação, na sua cultura, na dinâmica das relações que nela se estabelecem, nas suas contradições e conflitos, em seus consensos possíveis, na multiplicidade de vozes que desejam ser ouvidas, no intrincado tecido que constitui a comunidade acadêmica e científica. Respeitados esses princípios, faz sentido avaliar os desempenhos dos estudantes e das instituições formadoras. Faz sentido, portanto, considerá-la como instrumento de articulação de saberes e de comunidades de aprendizagens, num estímulo à mútua cooperação e às práticas formativas solidárias.Tomada como uma questão pública e não só técnica, tendo como suporte o compromisso ético-político com a defesa do caráter público e social da instituição universitária, a avaliação tem, pois, conseqüências não apenas restritas ao seu âmbito, mas repercussões na e para a sociedade.

\section{Para Concluir}

Nessa breve reconstituição do trabalho da Comissão Assessora, é importante destacar que, ao envolver representantes ligados a entidades da área e a instituições de educação superior, públicas e privadas, presentes nas cinco grandes 
regiões geográficas do país, a Comissão Assessora procurou tomar a avaliação como um potente recurso orientador para o aperfeiçoamento das instituições de ensino superior formadoras de professores, no âmbito dos cursos de Pedagogia, no conjunto do país.

Um sistema de avaliação torna-se bem sucedido quando subsidia a motivação, o interesse, a busca coletiva do aperfeiçoamento de todo o sistema de educação em seus diversos aspectos e inter-relações com os demais níveis e modalidades de ensino. A conjugação desses fundamentos e o que está posto pelo Sistema Nacional de Avaliação da Educação Superior (SINAES) em que o Exame Nacional de Desempenho dos Estudantes (ENADE) é uma importante etapa, permitiu, portanto, que a Comissão ciente de sua responsabilidade, conduzisse seu trabalho com forte empenho na realização das tarefas a ela demandada.

Os processos de avaliação não têm um fim em si mesmos. Os indicadores da realidade definidos como suporte para processos de interpretação e comparação entre referenciais são construções ideais e históricas e não podem ser tomados como algo definitivo e inquestionável. São padrões de qualidade necessários em projetos definidos por metas e objetivos específicos e situados no tempo e no espaço. Isso significa que uma verdadeira avaliação institucional liga-se diretamente a um processo sistemático de análise na perspectiva da instituição compreender-se a si própria, suas dimensões e formas de atuação, seus resultados e projetos, sua história de empreendimentos acadêmicos com vistas a estimular o seu aperfeiçoamento. É, portanto, um processo que envolve tanto o auto-conhecimento quanto análise de desempenho nas diferentes dimensões - ensino, pesquisa, extensão e gestão.Vista, nessa perspectiva a avaliação institucional coloca em evidência as instituições com suas crenças, valores e práticas.

A proposta contida nos dispositivos legais que criam e regulamentam o SINAES evidencia o caráter formativo do modelo de avaliação proposto como se pode verificar em vários documentos produzidos pelo INEP:

A avaliação das instituições de educação superior tem caráter formativo e visa o aperfeiçoamento dos agentes da comunidade acadêmica e da instituição como um todo.Tal ocorre, em especial, quando conta com a participação efetiva de toda a comunidade interna e, ainda, com a contribuição de atores externos do entorno institucional.(BRASIL. MEC.INEP, 2004, p. 9)

O objetivo geral dessas políticas é monitorar a qualidade do ensino, verificar a equidade e a eficiência dos sistemas de educação. Para isso, as propostas pretendem desenvolver indicadores de qualidade, de eqüidade e de eficiência 
do sistema, na perspectiva de identificar problemas e diferenças em termos regionais e fatores que influenciam no desempenho dos alunos; oferecer informações técnicas e gerenciais aos administradores da educação pública, para que possam formular e avaliar programas de melhoria da qualidade do ensino; proporcionar à sociedade uma visão clara e concreta dos resultados dos processos de ensino e das condições em que são desenvolvidos; consolidar competências técnicas e científicas na área da avaliação educacional, ativando o intercâmbio entre instituições de ensino e pesquisa; comparar desempenho dos alunos e do sistema educacional brasileiro com o de outros países.

A proposta SINAES, conceitualmente, congrega princípios como o diagnóstico, a auto-formação, a ênfase no processo de construção da informação e na perspectiva de crescimento e transformação institucional. Esse tipo de avaliação implica pensar a instituição em seu conjunto, na multiplicidade de interações que a fazem e que definem as suas ações, envolvendo mecanismos importantes para a mobilização da comunidade acadêmica na reflexão sobre suas ações. São processos complexos na verdade e se transformam em grandes desafios, já que exigem que a prática institucional se transforme no próprio objetivo de investigação. No entanto, é interessante considerar que podem levar ao crescimento e à garantia de sua legitimidade acadêmica.

A identidade de uma Universidade se expressa em seus princípios éticopolíticos concretizados nas suas atividades de ensino, pesquisa, extensão e gestão. Nesse sentido, os dados produzidos pelo ENADE, pertencentes a uma política maior de avaliação, teriam como condição primeira e fundamental promover o encaminhamento de um processo capaz de favorecer a definição de uma política maior de crescimento da qualidade de ensino superior no país. Isto significa que a partir da socialização dos resultados, as instituições deveriam se debruçar sobre eles e compará-los ao conhecimento que detém do seu próprio projeto institucional, do seu plano pedagógico e, em particular, daquilo que reconhecem como referencial de análise de sua prática. Neste contexto, algumas questões mereceriam serem consideradas pelas instituições diante dos dados apresentados: o que se fará com os diagnósticos desenvolvidos? Quem será o responsável direto pelas alterações consideradas necessárias? Qual será o lugar do governo no encaminhamento das melhorias necessárias, tanto no caso das IES públicas quanto no caso das IES privadas?

Conhecendo a complexidade dessa tarefa, esperamos, portanto, havermos contribuído para desenvolver um processo que "efetivamente vincule a dimensão formativa a um projeto de sociedade comprometida com a justiça e a igualdade social", fundamentos esses presentes nos documentos que definem a concepção do SINAES. 


\section{Referências}

BRASIL. MINISTÉRIO DA EDUCAÇÃO. INSTITUTO NACIONAL DE ESTUDOS E PESQUISAS EDUCACIONAIS ANÍSIO TEIXEIRA. Manual do Exame Nacional de Desempenho dos Estudantes ENADE - 2004. Brasília: INEP, 2004.

BRASIL. MINISTÉRIO DA EDUCAÇÃO. INSTITUTO NACIONAL DE ESTUDOS E PESQUISAS. Relatório Final da Comissão de Avaliação da Pedagogia - Provão 2002. Brasília: INEP, 2002.

DIAS SOBRINHO, José. Avaliação da educação superior. Petrópolis: Vozes, 2000.

FREIRE, Paulo. Pedagogia da esperança: um reencontro com a pedagogia do oprimido. Rio de Janeiro: Paz e Terra, 1992.

JONNAERT, P.; BARRETTE, J.; BOUFRAHI, S.; MASCIOTRA, D. Contribution critique au développement des programmes d'enseignement : compétences, constructivisme et interdisciplinarité. Notes de synthèse. Révue des Sciences de l'éducation, v. 30, n. 3, p. 667-696, 2005.

LIMANA, Amir; BRITO, Márcia Regina Ferreira. O modelo de avaliação dinâmica e o desenvolvimento de competências: algumas considerações a respeito do ENADE. Avaliação: Revista da Rede de Avaliação Institucional da Educação Superior, Campinas, v. 10, n. 2, p. 9-32, jun. 2005.

SILVA, Carmem S. Bissolli da. Curso de pedagogia no Brasil: história e identidade. Campinas,SP : Autores Associados, 1999.

SINAES.INEP. Sistema Nacional de Avaliação da Educação Superior: da concepção à regulamentação. 2. ed. ampl. Brasília: INEP, 2004. 